\title{
Statistical Measurement of Service Quality in Tanzania Industries: A Case of Said Salim Bakhresa \& Co Ltd.
}

\author{
Abbas Ismail (Corresponding author) \\ Dept. of Statistics, University of Dodoma \\ P. O. Box 338, Dodoma, Tanzania \\ Mobile: 071799012 E-mail: abbasism2003@yahoo.co.uk \\ Peter Josephat \\ Dept. of Statistics, University of Dodoma \\ P. O. Box 338, Dodoma, Tanzania \\ Mobile: 0787288998 E-mail: mtakwimu@yahoo.com
}

Accepted: October 05, 2012 Published: November 22, 2012

Doi:10.5296/ijhrs.v2i4.2638 URL: http://dx.doi.org/10.5296/ijhrs.v2i4.2638

\begin{abstract}
The study aimed to use statistical techniques to measure quality of services produced by Said Salim Bakhresa \& Co Ltd. The study was conducted among wholesalers and bakeries who sell wheat flour produced by the company. These were selected from four different locations representing the major towns where the wheat flour and its products are widely consumed. These are Dar es Salaam, Morogoro, Arusha, Moshi and Tanga. Sample size for the study was 434. The study employed the cross-sectional study design and pre structured questionnaire was used to collect data.
\end{abstract}

Factor analysis and regression analysis are statistical techniques performed. From eleven attributes outlined by ISO: 9000: 2008, the factor analysis formed four components: product quality; packaging; timeliness and promptness; and customer care. The findings show that all the components achieved good quality level because all have quality scale index less than 2.99. Regression analysis was adopted to generate ISO-Quality model, model shows that among the four components of qualities, two components (product quality and customer care) are statistically significant related with the company being ISO certified. In general product quality and packaging seem to perform better than the rest of the components.

Keywords: ISO 9001:2008, Quality, Product, Quality index scale, ANOVA

\section{Introduction}

The continuous change in the customer needs has led into a rapid evolution in the markets. Within a very short duration there is always significant change in customer's behavior and 
markets. This rapid change always makes it difficult to maintain a stable relationship between the customers and suppliers. Many organizations nowadays are seeking for the programs which may continuously commit them to offer the high quality product and customer satisfaction. Within the past ten years, it is witnessed that a substantial number of organizations in Tanzania started adapting the Quality Management System (QMS) i.e. International Organization for Standardization (ISO) 9001:2008 as an approach to enhance and sustain their product qualities and therefore to fulfill their customer needs and wants (Mvungi, 2012).

Service quality has been associated with customer satisfaction. Customer satisfaction is the consumer's feelings of pleasure or disappointment that results from comparing a product's perceived performance (or outcome) to their expectations. If the performance falls short of expectations, customer is dissatisfied and disappointed. If it matches expectations the customer is highly satisfied or delighted (Kotler et al., 2009). According to Leen and Yoon (2004), customer satisfaction is a broad concept that includes perceived evaluation of product and service. The concept of customer satisfaction is relevant to our study because any successful Quality Management System implementation should end up with the products and services that satisfy the users.

Parasuraman et al. (1985) defined quality of services as the difference between consumers' perceptions of the service received, compared with their expectations of service experiences. It reflects both objectives and subjective aspects of services. Kotler et al. (2009) explained that seller has delivered quality whenever its products or service meets or exceeds the customer's expectations. A company that satisfies most of its customers' needs it is called a quality company.

In the context of milling technology, National Association of British and Irish Millers (NABIM) narrates that, quality does not always means the very best i.e the highest protein content flour from the strongest grist. What it means is something which meets the customer's requirement or the thing that has fitness for purpose or use. It depends on what the customer is using for. Many customers regard consistency of flour as the most important factor in product quality (NABIM, 2001).

One way of winning customer satisfaction is to produce quality services. This concept has been adopted by several industries in order to keep them in business line. Because of this studies focused on customer satisfaction in relation to quality of service provided has increased. Unfortunately as described by Parasuraman et al. (1985) the accurate measurement of objective aspects of customer service requires the use of carefully predefined criteria. The measurement of subjective aspects of customer service depends on the conformity of the expected benefit with the perceived results. This in turns depend upon the customer's imagination of the service they might receive (Parasuraman et al., 1985). 
1.1 ISO 9001:2008 and Quality Management System

ISO 9001:2008 is one of elements of the ISO 9000 group of QMS which contains some requirements and guidelines which helps an organization achieve standards of quality. It defines set of quality standards that are determined as being necessary for manufacturers and service organizations to be effective competitor. The implementation of ISO 9000 can be used by the management of the company to improve performance and higher output (Raisinghani et al., 2005). According to Debby (2001) ISO 9001 standard is a management tool that focuses on meeting the customer needs and expectations.

When integrated into a process an ISO compliant system provides the foundation and structure through documentation and objective evidence that promotes consistency throughout the entire operation. This formalized documented system clearly defines management policy, objectives, and expected performance (Debby, 2001). Quality management system emphasize on eight principles which are: customer focus, leadership, involvement of people, process approach, system approach, continuous improvement, factual decision making, and mutually beneficial supplier relationships (ISO 9000:2000).

\subsection{The Concept of marketing in Quality Management System}

Marketing is termed as a process of identifying and meeting human and social needs. Therefore it is an organizational function and a set of processes for creating, communicating, and delivering value to customers and for managing customer relationships in ways that it benefits the organization and its stakeholders (Kotler 2009).

QMS in a company can become a potential marketing tool to accomplish its objectives of identifying and meeting the customers' needs. According to Bathie and Sarkar (2002) both marketing and QMS have core value in common and this is customer focus. In this case, total Quality Management can be potential for operationalizing marketing. According to Kotler et al. (2009), total quality is everyone's job, just as marketing is every ones job. Marketers play several roles in helping their companies define and deliver high quality goods and services to target customers.

\subsection{Said Salim Bakhresa (SS Bakhresa) Company profile}

S.S. Bakhresa \& Co Ltd is a flagship company of the Bakhresa Group. It was established in 1983, in the city of Dar es Salaam, Tanzania. It is the leading wheat flour manufacturing company in East and Central Africa, with a milling capacity of about 1,750 metric tons per day and combined silo storage capacity of 160,000 metric tons of wheat grains. Since its foundation the organization has been highly successful and profit making company in the private sector (Bakhresa Quality Manual, 2012).

The company has been consistently being expanded in its manufacturing capacity from 15 metric tons per day in the 1986 to $1,750 \mathrm{MT}$ /Day in 2012. This great success was largely contributed by good management strategy of the company and high demand of the product. The company used to manufacture superior products to cater for the needs and wants of 
several segments within and outside the country especially in the great lake countries (Bakhresa Quality Manual, 2012).

S.S. Bakhresa has three mills in Dar es Salaam; the oldest is Kipawa Flour Mill built in1986 with milling capacity of 15 metric tons per day located at Kipawa area in Dar es Salaam. This mill was labor intensive due to low level of technology at that time. Management constantly increased its capacity to 50 metric tons in 1990 and in 1996 and 2009 the plant was expanded to 240 and 250 metric tons per day respectively. In 1994, Bakhresa Group of companies acquired another milling plant at Zanzibar Isles; Zanzibar Milling Corporation( ZMC), which was also expanded to reach a milling capacity of 390 metric tons per day in 1996. The company continued to expand under the good leadership of Mr. Said Salim Awadhi Bakhresa who is the founder of the company. In 1999 the company acquired a land from the former National Milling Co-operation (NMC), and installed a state of art automated milling of 500mt capacity per day, Mzizima Flour Mill (MFM). This is located at Temeke District in Dar es Salaam region along Nyerere Road (Bakhresa Quality Manual, 2012).

Despite this expansion, the company was still not able to meet the demand. Around year 2003 and 2006 respectively the company installed two lines computerized milling units; Buguruni Flour Mills near Tanzania Zambia Railway (TAZARA) in Ilala where a former National Milling Co-operation was established. For all of this time the company was doing best by having a competitive advantage including its high milling technology, good product positioning and good marketing strategy compared to other existed mills, hence managed to posses high market share in the market (Bakhresa Quality Manual, 2012).

\section{Materials and Method}

\subsection{Respondents and Area of study}

The study was conducted among wholesalers and bakeries who sell wheat flour produced from S.S. Bakhresa \& Co. Ltd. These were selected from four different locations representing the major towns where the wheat flour and its products are widely consumed. These are Dar es Salaam, Morogoro, Arusha, Moshi and Tanga. Number of samples in each Region was determined based on probability proportional to size (pps).

Four regions were selected for study due to limited resources to cover the other regions, however, most of the wheat flour consumers are concentrated in these urban cities particularly Dar es Salaam and sample obtained termed as a true representative of the population.

\subsection{Sample size}

Random sample of 434 centres was included in the study from five regions of interest. The sample size was retrieved from Cochran's formula for determining the sample size.

Where $p=$ the sample proportion (i.e. the percentage of centres who were involved in the study and $q=1-p$ (those who were not involved). The value of $p$ equal to 0.5 which gave the 
optimal value of the sample size was adopted. $\mathrm{N}$ represents the total number of centres in five regions of interest selling wheat flour produced from Bakhresa Milling Industries. $Z_{\alpha / 2}$ is a constant associated with the confidence level that is being used. The level of significance $\alpha$ is $5 \%$; $e$ is the margin of error which is $5 \%$.

$$
n=\frac{N Z_{\alpha / 2}^{2} p q}{(N-1) e^{2}+p q Z_{\alpha / 2}^{2}}
$$

From the above information;

$$
\begin{gathered}
Z_{\alpha / 2}=Z_{0.05 / 2}=1.96, \quad e=0.05, \\
n=\frac{1458 \times 1.96^{2} \times 0.5 \times 0.5}{(1458-1) \times 0.05^{2}+0.5 \times 0.5 \times 1.96^{2}}=304.2133 \approx 304
\end{gathered}
$$

A minimum response rate of $70 \%$ was assumed in this study, which implies a non-response rate of at least $30 \%$. Taking on board this response rate, the adjusted sample size $n_{a}$ was:

$$
n_{a}=\frac{304}{0.7}=434.2857 \approx 434
$$

Hence, a sample of 434 centers was selected by taking into consideration the non-response which may be encountered during data collection.

\subsection{Sampling design}

This study employed the cross-sectional study design, using self-administered questionnaires. The sampling design was a stratified single-stage sampling design. Initially, the population was stratified into regions selected. Regarding the number of centers selling wheat flour in these five regions, there were five strata. One stratum is represented by one region selling wheat flour in wholesale business (i.e. Dar es Salaam, Arusha, Moshi, Morogoro and Tanga). During the first stage of the sampling design, a total number of 434 centers were selected out of 1,458 centers in all five regions mentioned. The selection of these centers was based on proportional allocation in each of the stratum. Again, the number of selected centers from each of the region was proportional to the size of the total number of centers in each particular region of study and was randomly selected. The complete sample based on this sampling design is summarized in Table 1 below.

Table 1: Sampling design

\begin{tabular}{|l|c|c|c|}
\hline \multicolumn{1}{|c|}{ Regions(stratum) } & No. of centers & Stratum weight & No. of centers selected \\
\hline Dar es salaam & $\mathrm{N}_{\mathrm{b}}=1302$ & 0.89 & $\mathrm{na}=386$ \\
\hline Morogoro & $\mathrm{Nb}=23$ & 0.02 & $\mathrm{nb}=9$ \\
\hline Arusha & $\mathrm{Nc}=41$ & 0.03 & $\mathrm{nc}=13$ \\
\hline
\end{tabular}




\begin{tabular}{|l|l|l|l|}
\hline Moshi & $\mathrm{N}_{\mathrm{d}}=57$ & 0.04 & $\mathrm{nd}=17$ \\
\hline Tanga & $\mathrm{N}_{\mathrm{e}}=35$ & 0.02 & $\mathrm{ne}=9$ \\
\hline Total & $\mathbf{N}=\mathbf{1 4 5 8}$ & & $\mathbf{n = 4 3 4}$ \\
\hline
\end{tabular}

\subsection{Data Collection}

A pre-structured questionnaire was used to interview respondents. Questionnaires were distributed to the centers selected in a sample and the filled questionnaires were collected immediately after the interview.

\subsection{Study variables}

Variables regarding customer's particulars like gender, experience with the company and type of the business whether bakeries or wholesalers were considered to select respondents. In addition product quality attributes customer service quality and ISO 9001 attributes were also taken into account during data collection.

\section{Results and Discussions}

The study intended to measure attributes of service quality developed by ISO 9001:2008 group of QMS. About eleven attributed were considered. These includes: Product quality performance; consistency in product quality; price in relation to the product; proper stitching and free from leakage; package appearance and labeling; net weight compliance; timeliness and promptness in product delivery; timeliness and promptness in sales service; customer communication and consultation; customer care and courtesy; and response on customer complaining. Enquiries regarding ISO certification were also included, which are; ISO certification has improved the quality of the products offered by the company, ISO certification has improved customer service quality offered by the company

Factor analysis was adapted to group factors based on Tanzania productions and marketing. To make sure the instrument has credibility for evaluating service quality in Tanzania industries, Bartlett's measure and sample adequacy test were performed; also validity test and reliability test were implemented.

Bartlett's measure test the null hypothesis that there is no correlation between variables against alternative hypothesis: there is relationship between variables. For factor analysis to work there should be some relationships between variables. From the data, Bartlett's test was significant since $p$ value is 0.000 which is less than 0.001 . This implies that there is relationship among variables which suggest the use of factor analysis.

Kaiser-Meyer-Olkin (KMO) is a measure of sampling adequacy. From the data, KMO value is 0.710 which means that there is positive relationship among variables. Kaiser (1974) recommended accepting values greater than 0.5 as acceptable. KMO value is close to 1 rather than 0 which implies patterns of correlations are relatively compact and so factor analysis should yield distinct and reliable factors. 


\section{Macrothink}

\subsection{Factor Analysis}

The essential purpose of factor analysis is to describe the covariance relationships among many variables in terms of a few underlying unobservable random quantities called factors. Variables can be grouped by their correlations, that is all variables within a particular group are highly correlated among themselves but have relatively small correlations with variables in a different group. Each group of variables represents a single underlying construct, or factor, that is responsible for the observed correlation (Johnson and Wichern, 1992).

\subsubsection{Scree plot}

The scree plot makes the choice on the number of factors to be retained. The number of factors to be retained was chosen by their position on the graph. All factors that lied above the point from the plot levels off to a linear decreasing pattern were retained. So from figure 1 it can be seen that after four factors a stable plateau was almost attained, therefore four factors were retained.

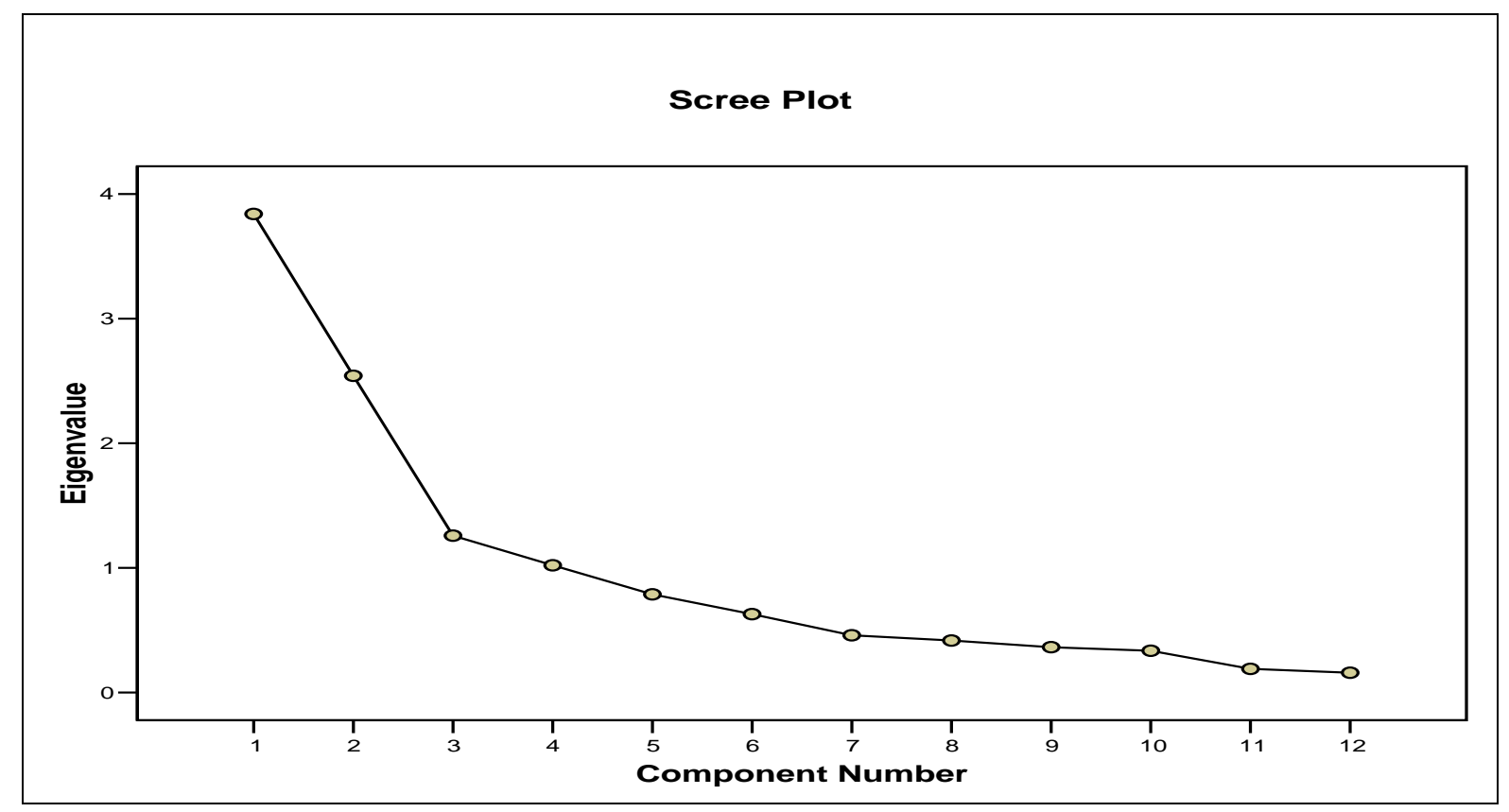

Figure 1: Scree plot for attributes of service quality

\subsubsection{Factor rotation}

In order to optimize the factors structure, factor rotation was performed. Four factors with equal relative importance have been created after extraction (see Table 2). 
Table 2: Rotated factor loading of four factors after varimax rotation

\begin{tabular}{|c|c|c|c|c|}
\hline Variables & 异 & 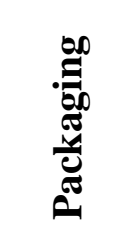 & 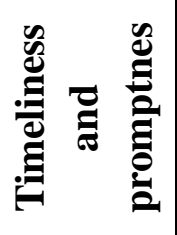 & 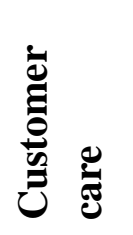 \\
\hline Product quality performance & 0.886 & & & \\
\hline Consistency in product quality & 0.866 & & & \\
\hline Price in relation to the product & 0.775 & & & \\
\hline Proper stitching and free from leakage & & 0.872 & & \\
\hline Package appearance and labeling & & 0.821 & & \\
\hline Net weight compliance & & 0.714 & & \\
\hline Timeliness and promptness in product delivery & & & 0.839 & \\
\hline Timeliness and promptness in sales service & & & 0.823 & \\
\hline Customer communication and consultation & & & & 0.799 \\
\hline Customer care and courtesy & & & & 0.729 \\
\hline Response on customer complaining & & & & 0.679 \\
\hline Eigenvalues & 2.637 & 2.151 & 2.002 & 1.871 \\
\hline$\%$ of variances & 21.972 & 17.924 & 16.681 & 15.592 \\
\hline Cumulative \% & 21.972 & 39.896 & 56.577 & 72.169 \\
\hline
\end{tabular}

Factor 1 accounted for $21.972 \%$, factor 2 accounted for $17.924 \%$, factor 3 accounted for $16.681 \%$ and factor 4 accounted for $15.592 \%$. All the four factors retained explained $72.169 \%$ of the total variance

\subsection{Reliability Analysis}

Reliability in this research refers to its ability to cope and manage the same value when measurement is replicated in another situation. According to Bruner and Hensel (1994) 'Alfa-Cronbach' is a standard method for measuring reliability of the study. In this study, the test of internal consistency is to carry out for determining the level of reliability of the instrument used. Internal consistency is determined by overall test and test according to components.

\subsubsection{Overall Test}

The test of consistency for overall items gives the high value of Alpha Cronbach (Yusoff et al., 2008) i.e. 0.781. As mentioned by Chua (2006) when Coefficient Alpha Cronbach produces the value 0.6 and above, it shows that the level of instrument is good and suitable to use. While Alpha Cronbach too low at the value below than 0.6, it shows that the instrument is having low reliability and the instrument should be improved. Consequently, this study shows the high level of instrument reliability and it is suitable to apply in this study. 


\section{Al Macrothink}

\subsubsection{According to Components}

The internal consistency tests on product quality, packaging, timeliness and promptness and customer care, gave Coefficient Alpha value of 0.866, 0.796, 0.699 and 0.624 respectively as shown in Table 3 below.

Table 3: Cronbach Alpha for Individual components

\begin{tabular}{|l|c|}
\hline Components & $\boldsymbol{\alpha}$-value \\
\hline Product quality & 0.866 \\
\hline Packaging & 0.796 \\
\hline Timeliness and Promptness & 0.699 \\
\hline Customer care & 0.624 \\
\hline
\end{tabular}

Through internal consistency test for overall items and through component of items the coefficient Alpha was ranging at the interval 0.866 to 0.624 . This shows the instrument have a reliability level and suitable for use in this study.

\subsection{Measurement of quality of services}

Service Quality is defined through comparison between customers' perception and expectation on services provided ( $\mathrm{SQ}=\mathrm{P} \mid \mathrm{E}$ ) (Yusoff et al., 2008). Scale 1 to 5 was used to calculate the Quality index.

According to the questionnaire: Five likert scales were used, numbered 1 to 5

1. Very satisfied

2. Satisfied

3. Neither satisfied nor unsatisfied

4. Dissatisfied

5. Very dissatisfied

Result of indices which explains quality of services are presented in table 4. Interpretation of the these indices is as follows;

Scale Index 2.99 to $1=$ the service is achieved good quality level

(Perception is higher than expectation)

Scale Index 3.00 to $3.9=$ The service achieved the minimum of quality level

(Expectation is equivalent to perception)

Scale Index 4.00 to $5.0=$ The service is below than quality level

(Perception is lower than expectation) 
Table 4: Quality Index Scale and Interpretations

\begin{tabular}{|c|c|c|}
\hline Component & Index & Interpretation \\
\hline \multicolumn{3}{|l|}{ Product quality } \\
\hline Product quality performance & 1.33 & the service is achieved good quality level \\
\hline Consistency in product quality & 1.43 & the service is achieved good quality level \\
\hline Price in relation to the product & 1.71 & the service is achieved good quality level \\
\hline \multicolumn{3}{|l|}{ Packaging } \\
\hline Proper stitching and free from leakage & 1.79 & the service is achieved good quality level \\
\hline Package appearance and labeling & 1.78 & the service is achieved good quality level \\
\hline Net weight compliance & 1.65 & the service is achieved good quality level \\
\hline \multicolumn{3}{|l|}{ Timeliness and promptness } \\
\hline $\begin{array}{l}\text { Timeliness and promptness in product } \\
\text { delivery }\end{array}$ & 2.32 & the service is achieved good quality level \\
\hline Timeliness and promptness in sales service & 2.11 & the service is achieved good quality level \\
\hline \multicolumn{3}{|l|}{ Customer care } \\
\hline Customer communication and consultation & 2.43 & the service is achieved good quality level \\
\hline Customer care and courtesy & 1.95 & the service is achieved good quality level \\
\hline Response on customer complaining & 2.07 & the service is achieved good quality level \\
\hline
\end{tabular}

All the components achieved good quality level because all have scale index less than 2.99. However, product quality and packaging appeared to score high values of good quality levels which implies, the company succeeded better in quality of the product and packaging. The least services achieved at the good quality levels were timeliness and promptness and customer care.

\subsection{ISO-Quality Model}

ISO quality model was developed through multiple linear regression technique. Explanatory variables were components of qualities and dependent variable was ISO attribute. Multiple linear regression was carried out to describe the functional relationship between ISO attributes and components of qualities. The intention was to observe whether the performances on quality by the company have any relationship with the company being ISO certified.

Relationship between these variables was determined by regression model,

$$
Y=\beta_{0}+\beta_{1} X_{1}+\beta_{2} X_{2}+\beta_{3} X_{3}+\beta_{4} X_{4}+\mu
$$

Where by $Y=$ Enquiry on ISO attributes, $\beta_{0}=$ constant term, $\beta_{1}=$ product quality, $\beta_{2}=$ packing variable, $\beta_{3}=$ timeliness and promptness, $\beta_{4}=$ customer care variable, $X_{i}=$ covariates, $\mathrm{i}=1,2,3,4$ 
To test whether there is statistical significance between the components of qualities and a company being ISO certified four hypotheses were formulated.

$$
\begin{array}{llll}
H_{0}: \beta_{1}=0 & H_{0}: \beta_{2}=0 & H_{0}: \beta_{3}=0 & H_{0}: \beta_{4}=0 \\
H_{1}: \beta_{1} \neq 0 & H_{1}: \beta_{2} \neq 0 & H_{1}: \beta_{3} \neq 0 & H_{1}: \beta_{4} \neq 0
\end{array}
$$

Before testing the individual contribution of factors to ISO, analysis of variance shows the four factors explain ISO attributes significantly as $p$ value is 0.000 . This implies that the model fit well the data. Other assumptions of regression were not performed because of implementing factor analysis. Contribution of each independent variable is presented in table 5 .

Table 5: Regression coefficients

\begin{tabular}{|l|c|c|c|c|c|}
\hline \multirow{2}{*}{ Model } & \multicolumn{2}{|c|}{$\begin{array}{c}\text { Unstandardized } \\
\text { Coefficients }\end{array}$} & $\begin{array}{c}\text { Standardized } \\
\text { Coefficients }\end{array}$ & $\mathrm{t}$ & Sig. \\
\cline { 2 - 6 } & $\mathrm{B}$ & Std. Error & Beta & & \\
\hline (Constant) & -0 & 0.043 & & -0.063 & 0.95 \\
\hline Product quality & 0.458 & 0.043 & 0.454 & 10.67 & 0.000 \\
\hline Packaging & 0.018 & 0.043 & 0.018 & 0.429 & 0.668 \\
\hline Timeliness and promptness & 0.03 & 0.043 & 0.029 & 0.691 & 0.49 \\
\hline Customer care & 0.186 & 0.043 & 0.184 & 4.329 & 0.000 \\
\hline
\end{tabular}

From the table, we reject null hypothesis for the first and fourth hypothesis about product quality and customer care respectively and we fail to reject null hypothesis for the second and third hypothesis about packaging and timeliness/promptness respectively.

Analysis of variance shows that among the four components of qualities, only two components were statistically significant related with the company being ISO certified. These components are product quality and customer care. Other two components were not statistically significant with company being ISO certified.

With reference to the previous measurement of quality index, it can be experienced that product quality has demonstrated the tremendous performance compared to customer care. The combined analysis (quality index and regression analysis) enclosed the facts that company being ISO certified has managed the company to produce the high quality products.

Equivalently, the performance of packaging services by the company as demonstrated from the quality index scale has nothing to do with the company being ISO certified, because, despite being an active component still not statistically significant with ISO attributes.

Since we failed to reject null hypothesis $\beta_{s}^{\prime}=0$ for the packaging; timeliness and 


\section{N Macrothink \\ International Journal of Human Resource Studies \\ ISSN 2162-3058 \\ 2012, Vol. 2, No. 4}

promptness, these variables are excluded from the equation since they are not associated with outcome of a company being ISO certified. New regression model after excluding the two components is

$$
\begin{aligned}
& \qquad \hat{Y}=0.458 X_{1}+0.186 X_{2} \\
& \hat{Y}-\text { Estimated outcome of a companybeing ISOcertified } \\
& X_{1}-\text { Product quality } \\
& X_{2}-\text { Customer care }
\end{aligned}
$$

The model explains that, a unit increase in customer care services leads to increase the performance of the company by being ISO certified by $18.6 \%$. The unit increase in producing the quality products leads to increase the performance of the company by being ISO certified by $45.8 \%$. This implies, by introducing each batch of the quality products in the market increases the performance of the company by being ISO certified by approximately $50 \%$.

\section{Conclusion}

In general, the product quality, packaging, timeliness/promptness and customer care seems to perform well in quality levels. Moreover, product quality and packaging seem to perform better than the rest of the components. However, ISO 9001:2008 contributed much in the quality of the products and little in customer care. Efforts are needed to improve more on timeliness and promptness.

\section{Recommendation}

Concentration of the research was on a single product (wheat flour and its products); further researches should include varieties of the products whose companies are certified under ISO.

\section{Acknowledgements}

We give much thanks to Mr. Iddi Hatibu Mvungi who is Miller and Quality Assurance Manager at the Said Salim Bakhresa \& Co Ltd for helping us with data.

\section{Competing Interests}

The authors declare that they have no competing interests

\section{Corresponding author}

Abbas Ismail

Dept. of Statistics, University of Dodoma

P. O. Box 338, Dodoma, Tanzania

E-mail: abbasism2003@yahoo.co.uk 


\section{Al Macrothink}

International Journal of Human Resource Studies

ISSN 2162-3058

2012, Vol. 2, No. 4

\section{References}

Bathie, D. and Sarkar, J. (2002). Total Quality marketing (TQMk). A Symbiosis Managerial Auditing Journal 17(5): pg 241-244.

Bruner, G. and P. Hensel (1994). Marketing Scales Handbook: A Compilation of Multi-item Measures. Chicago Illinois: American Marketing Association

Chua, Y. P. (2006). Asas statistik Penyelidikan- Kaedah dan Statistik Penyelidikan-Buku 2. Kuala Lumpur: Mc Graw Hill Education. pp. 1-201.

Debby, L. N. (2001). The ISO 9000 quality System: Application in Food Technology. Orlando Florida-USA.

International Standard ISO 9000:2000. Quality Management Systems (2000)-Fundamentals and Vocabulary.

ISO 9001:2008. International Standards, Quality Management Requirements. 4th edition

Johnson, R.A., and Wichern, D.W. (1992). Applied Multivariate Statistical Analysis ( ${ }^{\text {rd }}$ Edn). New Jersey: Prentice Hall Inc and ISBN: 0130418072, pp 396.

Kaiser, H.F. (1974). An Index of Factorial Simplicity. Psychometrika, 39, 31-36.

Kottler, P., and Keller, K. (2009). Marketing Management 13th edition. Pearson Education Ltd, London.

Leem, C. S and Yoon, Y. (2004). A Maturity Model and an Evaluation System of Software Customer Satisfaction: The Case of Software Companies in Korea. Industrial Management \& Data Systems 104 (4): 347-5

Mvungi, H. I. (2012). "The effect of QMS on Customer Satisfaction in Tanzania Industries". M.A dissertation, Business Administration, UDSM, Tanzania (Unpublished).

National Association of British and Irish Millers (NABIM) (2001). The Flour, 3rd edition. 21 Arlington Street, London UK.

Parasuraman, A., Zeithaml, V. A., and Berry, L. L. (1985). A conceptual model of service Quality and its implications for future research. Journal of Marketing, 49, 41-50. 
Raisinghani, M. S., Ette, H., Pierce, R., Cannon, G. and Daripaly, P. (2005). Six Sigma: Concepts, Tools, and Applications. Industrial Management and Data Systems: 491-505.

S. S. Bakhresa (2011). Quality Manual . Retrieved from w.w.w:Bakhresa.com on September, 2012.

Yusoff, W. Z. W. and Ismail, M. (2008). FM-Serqual: A New Approach of Service Quality Measurement Framework in Local Authorities. Pacific Rim Real Estate Society, Malaysia. 